\title{
Gastric Neuroendocrine Tumors (G-Nets): Incidence, Prognosis and Recent Trend Toward Improved Survival
}

\author{
Zhen Yang ${ }^{a}$ WeiHua Wang JingFeng Lu ${ }^{a, b}$ Gaofeng Pan ${ }^{a}$ Zhiyu Pan ${ }^{a}$ \\ Qian Chen ${ }^{\mathrm{a}}$ Weiyan Liu ${ }^{\mathrm{a}}$ Yanping Zhao a.c
}

aDepartment of General surgery, Minhang Hospital, Fudan University, Minhang, Shanghai, bDepartment of Thoracic surgery, Minhang Hospital, Fudan University, Minhang, Shanghai, 'Department of Gastroenterology, Minhang Hospital, Fudan University, Minhang, Shanghai, People's Republic of China

\section{Key Words}

Incidence $\bullet$ Survival status $•$ Gastric neuroendocrine tumors

\begin{abstract}
Background/Aims: Gastric neuroendocrine tumors (G-NETs) are uncommon neoplasms that can present with or without clinical symptoms. In this study, we evaluated the incidence, prognosis, and temporal trends of G-NETs. Methods: We analyzed all cases of G-NETs registered in the Surveillance, Epidemiology, and End Results (SEER) database from 1973 to 2014. Incidence was estimated by age and joinpoint analyses. Survival rates were calculated and survival trends over time were evaluated. Results: A total of 3740 eligible patients were enrolled in the study. G-NETs incidence increased from 0.31 per 1000000 patients in 1975 to 4.85 in 2014, with an annual percentage changes (APCs) of $8.9 \%$ (95\% confidence interval [CI] $=7.7 \%$ to $10.21 \%, P<0.001$, t test (29) from 1975 to 2001 and $3.6 \%$ from 2002 to 2014 (95\% $\mathrm{CI}=2.3 \%$ to $4.9 \%, P<0.001$ ). For cases diagnosed between 1973 and 1982, five-year survival was $62.8 \% \pm 7.0 \%$ (Standard error, SE) and increased to $86.7 \% \pm 0.7 \%$ for cases diagnosed between 2003 and 2012 ( $P<0.001)$. Years of diagnosis, gender, age at diagnosis, marital status, grade, tumor size, tumor stage, and surgery performed or not were the strongest predictors of worse survival in both univariate and multivariate analysis $(P<0.05)$. Conclusion: G-NETs are uncommon neoplasms but the incidence is growing. Survival has improved in the past decades. Years of diagnosis, gender, age at diagnosis, marital status, grade, tumor size, tumor stage, and surgery status predict survival in patients with G-NETs.
\end{abstract}

(C) 2018 The Author(s)

Published by S. Karger AG, Basel

\section{Introduction}

Neuroendocrine tumours (NETs), known historically as carcinoid tumors, were first described by Lubarsch in 1888. These tumors are distributed throughout the body but are mainly found within the gastrointestinal (GI) tract [1-3]. Using data gathered from 1973 to Z. Yang and W. Wang contributed equally to this work.

Yanping Zhao and Weiyan Liu
Department of Gastroenterology, Department of General surgery

Minhang Hospital, Fudan University, 170 Xinsong Road,Minhang, Shanghai (China)

E-Mail zhaoyp_sh@sina.com, weiyanliufudan@163.com

\section{KARGER}


2004 from an epidemiological database in the United States, the Surveillance Epidemiology and End Results (SEER) study reports the incidence of NETs as 5.25 per 100.000 persons [4]. The incidence and prevalence of these tumors have been increasing in recent decades [5]. Widespread endoscopic screening, increased awareness of the neuroendocrine histology, and/or improved data capture likely have contributed to the early detection of tumors.

The treatment and the prognosis of patients with NET depend on the grade of differentiation and the stage of the tumor. For example, well-differentiated NETs can be effectively treated by somatostatin analogues, whereas the poorly differentiated NETs generally require more aggressive treatment such as surgery and chemotherapy [5]. New drugs, such as some tyrosine kinase inhibitors, have demonstrated a benefit on overall survival for well-differentiated NETs, but they have yet to be approved for the regulatory agencies [5-7]. In the same way, the prognosis of patients is better if NET is diagnosed at early stage than those at advanced stage [8].

NETs of the stomach are rare and comprise about $0.1-0.6 \%$ of all gastric cancers [9], and represent about $7 \%$ to $8 \%$ of all NETs $[1,10]$. In fact, NETs-GI is a heterogeneous group of tumors which present with variety of clinical symptoms. Multiple factors may influence the malignant potential of the NETand the tumor site is one of pivotal factors determined the malignant potential of the tumor. There is few information available about the incidence and survival changes of G-NETs in the past decades. Moreover, in many published trials, G-NETs are lumped together with other GI-NETs and the results are difficult to analyze.

Hence, in this study, we estimate the incidence of NETs arising in the stomach in the SEER database. We also report the survival changes in 1975-2014 and the prognostic factor for survival after surgery for 1975-2012.

\section{Materials and Methods}

\section{Patients}

Two cohorts of patients with microscopically confirmed G-NETs were created using the SEER database (additional inclusion and exclusion criteria detailed below). This study was approved by the Review Board of Minhang Hospital, Fudan Universiy.

\section{Cohort to Estimate G-NETS Incidence: SEER 9, 1975-2014}

One cohort, created to estimate long-term incidence, included G-NETs diagnosed in SEER 9 registries from 1975 to 2014. All cases with unknown age at time of diagnosis were excluded for the incidencecalculated as age-adjust incidence. The diagnosis of G-NETs was based on CS Schema v0204+ which classification as NETstomach. The NETstomach coding is equivalent with 8153/3: Gastrinoma, malignant, 8246/3: Neuroendocrine carcinoma, NOS, and 8249/3: Atypical carcinoid tumor based on International Classification of Diseases for Oncology, Third Edition (ICD-0-3). No other restrictions were applied.

Cohort to Estimate the Treatment and Survival of G-NETs: SEER 18, 1973-2012

A second cohort was created to estimate the use of surgical therapy and survival information. Data for the SEER 18 registries, covering 28\% of the US population, were selected to allow for subtype analyses while maintaining a consistent population. Cases were eligible if diagnosed from 1973 to 2012 with G-NETs. In order to guarantee a sufficient follow-up time, patients diagnosed after 2012 were excluded from the analyses. Cases with no survival information were excluded from the study.

\section{Statistical Analyses}

Incidence was estimated as diagnoses per 1000000 patients per year (SEER*Stat software, version 8.3.4, Information Management Services, Incorporated, Calverton, MD). Changes in incidence were assessed and fit (Joinpoint Regression Program version 4.2, Information Management Services, Incorporated, Calverton, MD) using log-linear models and annual percentage changes (APCs) estimated for the final, best fitting model. Differences in trends were also assessed [11]. SEER 9 registry data from 1975 to 2014 was used to estimate long-term trends.

\section{KARGER}


Because a unified staging system for NETs is lacking, the SEER staging system was used for analysis. Tumors were classified as localized, regional, or distant. A localized NET was defined as an invasive neoplasm confined entirely to the organ of origin. A regional NET was defined as a neoplasm that (1) extended beyond the limits of the organ of origin directly into surrounding organs or tissue, (2) involved regional lymph nodes, or (3) fulfilled both of the aforementioned criteria. Finally, a distant NET was defined as a neoplasm that spread to parts of the body remote from the primary tumor [12].

There is no accepted uniformed grading system for malignant NETs. Pathologists in the United States typically use the terms "carcinoid tumor" to denote well-differentiated NETs (G1). The term "atypical carcinoid" is frequently used to describe a moderately differentiated carcinoid and is classified as G2 tumor, poorly differentiated tumors are classified as G3 tumors, and anaplastic tumors are classified as G4 tumors [12].

Survival analyses were conducted using the SPSS 17.0 statistical software package for the SEER18 cohort, diagnosed 1975-2012. Survival curves were plotted by Kaplan-Meier method and compared by logrank test. The significance of various survival-related variables was assessed by Cox regression model in the multivariate analysis. $\mathrm{P}<0.05$ was considered statistically significant.

\section{Results}

\section{G-NETs Incidence}

G-NETs incidence increased from 0.31 per 1000000 patients (hereafter all incidence estimates are per 1000000 women) in 1975 to 4.85 in 2014, with an APC of 8.9\% (95\% confidence interval $[\mathrm{CI}]=7.7 \%$ to $10.21 \%, P<0.001$, t test (29) from 1975 to 2001 and $3.6 \%$ from 2002 to 2014 (95\% CI= 2.3\% to $4.9 \%, P<0.001$ ) (Fig. 1).

At the same time, the incidence of systemic NETs presentations increased from 15.82 in 1975 to 78.85 in 2014, with an APC of increased at $19.5 \%$ (95\% CI= 0.5\% to 42.1\%, P < 0.001 ) from 1983 to $1986,4.7 \%$ from 1986 to $2003(95 \% \mathrm{CI}=4.3 \%$ to $5.1 \%, \mathrm{P}<0.001$ ) and $3.3 \%$ from 2003 to 2014 ( $95 \%$ CI=2.8\% to $3.8 \%$, P < 0.001 ), but there was no significant change in incidence from 1975 to 1983.

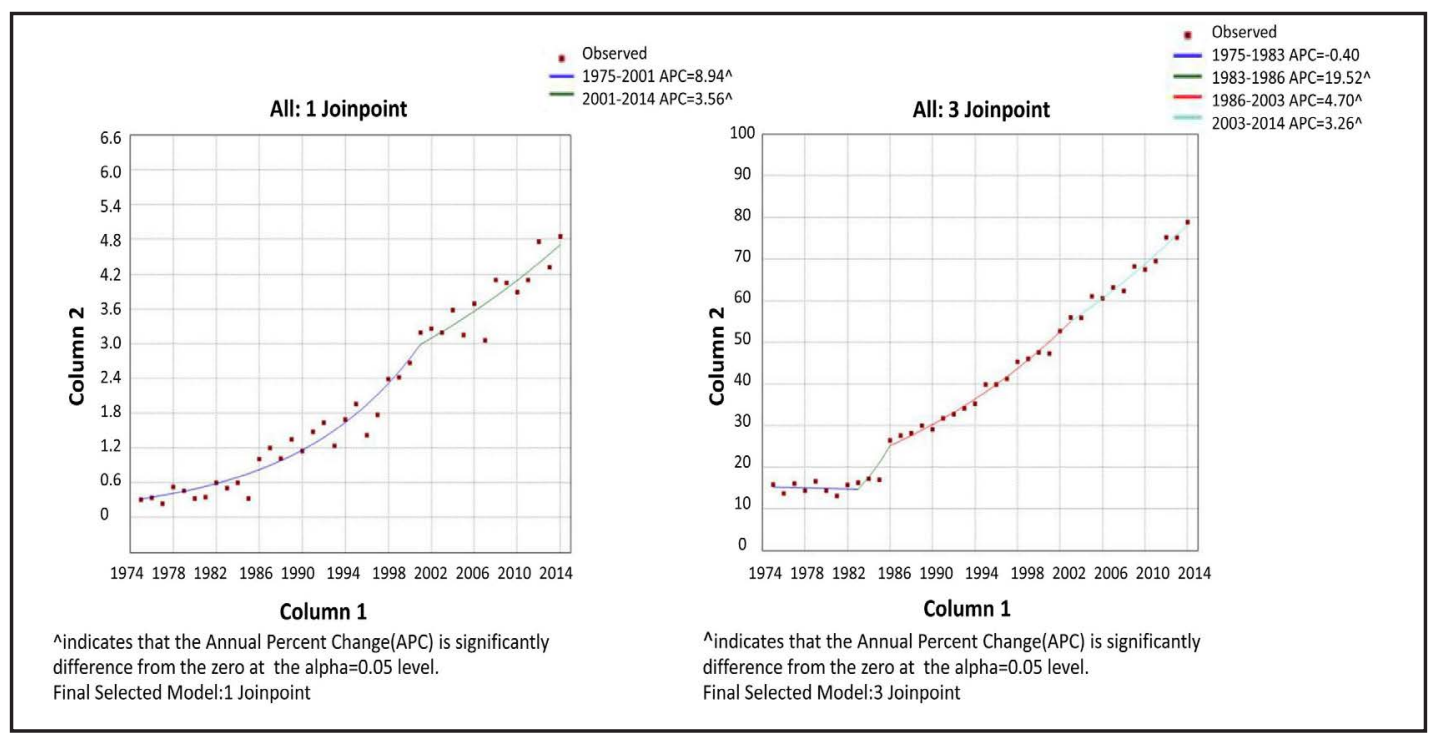

Fig. 1. These graphs show the incidence of neuroendocrine tumors (NETs) over time. (A) Annual ageadjusted incidence of G-NETs by year (1973 to 20014). The incidence is presented as the number of tumors per 100,000 age-adjusted for the 2000 US standard population. (B) Time-trend analyses of the incidence of total NETs (1973 to 2014).

\section{KARGER}


Fig. 2. Survival duration by period of diagnosis. Patients were separated into four groups by year of diagnosis. (A) The 5 -year CSS was $62.8 \%, 75.3 \%$, $81.2 \%, 86.2 \%$ for those diagnosed among 1973-1982, 1983-1992, 1993-2002, 20032012 ( $\left.\chi^{2}=21 . .617, \mathrm{P}<0.001\right)$. (B) Patients with regional disease had an improvement in median survival duration $(\mathrm{P}<0.001)$. There were no significant improvements in survival duration among patients with localized (C) or distant disease (D).

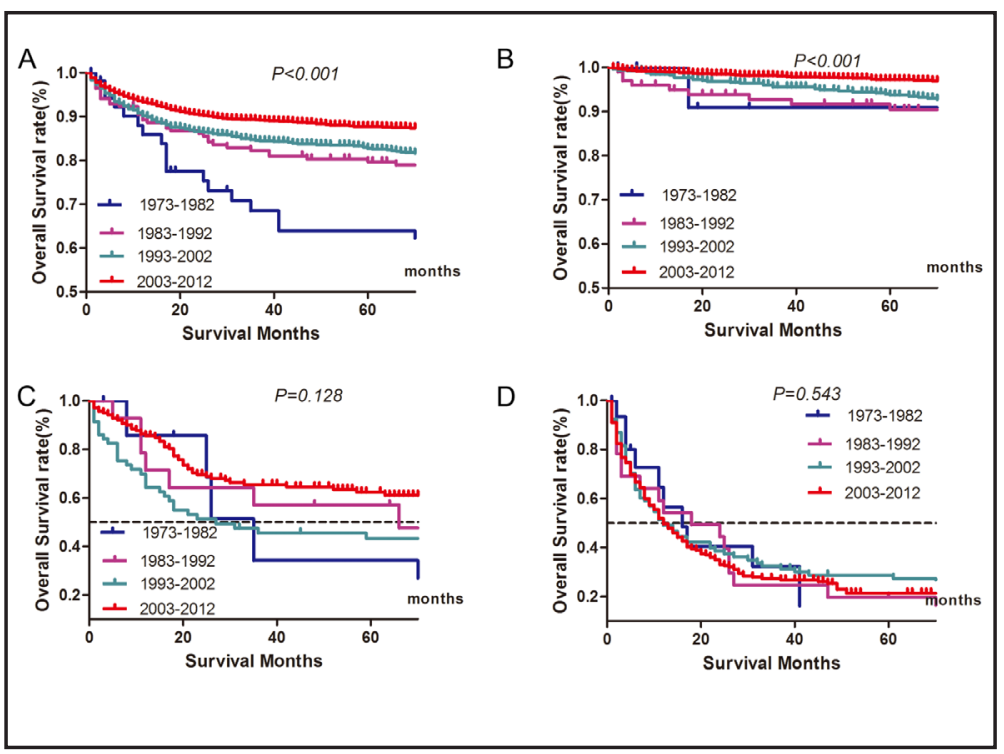

G-NETS Five-Year cause specific Survival

For the number of patients diagnosed with G-NETs was small in the first decade since 1973 . We used the SEER18 cohort to compare the survival rate improvement in the past 40 years. The cohort was divided into four subgroups by every ten years.

A total 3, 740 patients were included in the study, including 1497 male and 2243 female patients. The patients' characteristics were summarized in Table 1. Five-year cause specific survival for G-NETs improved markedly from the first 10 years to latest 10 years. For cases diagnosed between 1973 and 1982, fiveyear survival was $62.8 \% \pm 7.0 \%$ (Standard error, SE) and increased to $86.7 \% \pm 0.7 \%$ for cases diagnosed between 2003 and 2012 ( $\mathrm{P}<0.001$ ) (Fig. 2A). Improvement in survival was slightly for systemic NETs, increasing from $70.63 \% \pm 1.02 \%$ to $73.59 \% \pm 0.38 \%$ for the same respective Table 1. Patient and tumor characteristics of G-NETs diagnosed in SEER 18 registries, 1973-2012

\begin{tabular}{|c|c|c|}
\hline Characteristic & No. & $\%$ \\
\hline Sample size & 3740 & $100 \%$ \\
\hline Median age, year & 61 & \\
\hline \multicolumn{3}{|l|}{ Age at diagnosis } \\
\hline Younger than age 60 & 1665 & $44.5 \%$ \\
\hline Age 60 years older & 2075 & $55.5 \%$ \\
\hline \multicolumn{3}{|l|}{ Sex } \\
\hline Male & 1497 & $40.0 \%$ \\
\hline Female & 2243 & $60.0 \%$ \\
\hline \multicolumn{3}{|l|}{ Years of diagnosis } \\
\hline $1973-1982$ & 55 & $1.5 \%$ \\
\hline 1983-1992 & 184 & $4.9 \%$ \\
\hline $1993-2002$ & 900 & $24.1 \%$ \\
\hline $2003-2012$ & 2601 & $69.5 \%$ \\
\hline Surgery & 550 & $14.2 \%$ \\
\hline Performed & 2214 & $59.2 \%$ \\
\hline Not Performed & 1449 & $38.7 \%$ \\
\hline Unknown & 77 & $2.1 \%$ \\
\hline \multicolumn{3}{|c|}{ Stage(Ann Arbor Stage,1983+) } \\
\hline Regional & 2403 & $64.3 \%$ \\
\hline Localize & 241 & $6.2 \%$ \\
\hline Distant & 421 & $11.3 \%$ \\
\hline Unknown & 685 & $18.3 \%$ \\
\hline \multicolumn{3}{|l|}{ Primary site } \\
\hline Cardia & 280 & $7.5 \%$ \\
\hline Fundus of stomach & 435 & $11.6 \%$ \\
\hline Body of stomach & 902 & $24.1 \%$ \\
\hline Gastric antrum & 351 & $9.4 \%$ \\
\hline Pylorus & 52 & $1.4 \%$ \\
\hline Lesser curvature & 198 & $5.3 \%$ \\
\hline Greater curvature & 254 & $6.8 \%$ \\
\hline Overlapping lesion & 168 & $4.5 \%$ \\
\hline Stomach, NOS & 1100 & $29.4 \%$ \\
\hline
\end{tabular}
time periods $(\mathrm{P}<0.05)$.

Five-year survival tended to be increased significantly for those presenting with Localized stage. The 5-year CSS was 90.9\%, 89.6\%, 93.2\%, 96.8\% for those diagnosed among 19731982, 1983-1992, 1993-2002, 2003-2012 ( $\left.\chi^{2}=21 . .617, \mathrm{P}<0.001\right)(F i g .2 \mathrm{~B})$. Although there was apparent improvement in survival for patients at Regional stage, but the difference was not statistical (5-year CSS was 34.3\%, 53.3\%, 42.6\%, 59.9\% for the same respective time periods, $\chi^{2}=5.678, P=0.128$ ) (Fig. $2 \mathrm{C}$ ). The difference for patients at Distant stage is also not statistical significance $\left(\chi^{2}=2.145, P=0.543\right)$ (Fig. 2D).

\section{Factors associated with prognosis of G-NETs}

We found several factors, including years of diagnosis $(\mathrm{P}<0.001)$, gender $(\mathrm{P}<0.001)$, age at diagnosis $(\mathrm{P}<0.001)$, marital status $(\mathrm{P}<0.001)$, grade $(\mathrm{P}<0.001)$, tumor size $(\mathrm{P}$ 


\section{Cellular Physiology Cell Physiol Biochem 2018;45:389-396

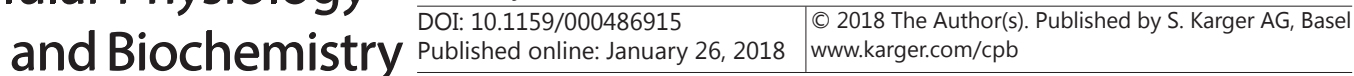 \\ Yang et al.: Gastric Neuroendocrine Tumors Epidemiology}

$<0.001)$, stage $(\mathrm{P}<0.001)$, and surgery performed or not $(\mathrm{P}<0.001)$, to be potential predictors of outcome (Table 2). In multivariate analysis, all the above factors were validated as independent predictor of survival $(\mathrm{P}<0.05)$. Using diagnosis year 1973-1982 as reference, the improvement in survival of year 1983-1992 was not significant $(\mathrm{P}=0.491)$, but after year 1983, the survival rate was further improvement and the difference reached statistical significance $(\mathrm{P}<0.01)$ (Table 2). We also found the tumor stage to be a powerful predictor of survival outcome $(\mathrm{P}<0.001)$. The survival rate for patients with localized, regional and distant was $95.6 \%, 54.3 \%$ and $20.4 \%$, respectively. There was 6.32 -folds increased in mortality from G-NETs in patients diagnosed with regional stage than those diagnosed with localized stage, and 13.845 folds increased in mortality for distant stage when compared with localized stage $(\mathrm{P}<0.001) \quad($ Table 2). As anticipated, large tumor size, elder patients, poor differentiate grade, and non-surgical therapy were validated as independent prognostic factor for G-NETs. Interestingly, female and unmarried patients were unfavorable prognostic factors for those patients.

\section{Discussion}

In present study, we took advantage of the vast amount of data from the SEER Program to examine the largest series of G-NET cases reported to date with a focus on incidence, prevalence, and prognostic factors. Similar to those of previous reports on systematic NETs [3-5], our results indicated a significant increase in the reported incidence of NETs through the years. This increase was likely due to the improvements in classification of these tumors. Also, widespread use of endoscopy for cancer screening contributed to the increase in reported incidence of digestive tract NETs [4]. Despite this, widespread use of gastric acid inhibitors such as proton pump inhibitors, the changes of lifestyle may also be attributed to the increasing incidence $[1,13]$.

Despite the fact that the annual prevalence of G-NENs has been increased globally in recent decades, data on factors associated with G-NENs prognosis has been poorly described, because of their rarity and with a spectrum of organic behaviors from benign to malignant [14]. Thus, our study provided comprehensive information on the prognosis of G-NENs with a large sample. Some findings in present study is very interesting. First, there was an apparently improvement in survival in the study periods. Surgical removal of tumors is the only potentially curative approach for G-NETs. Even in the presence of distant metastases, gastric surgery may be benefit [15-17]. Management dilemmas may be posed by the usually for G-NET at localized or distant stage. The advent of somatostatin and its analogues has generated new prospects for medical treatment of SRS-positive metastatic NETs. Ferraro et al. showed that administration of octreotide controlled the growth of ECL cells in the setting of atrophic gastritis- related hypergastrinemia [18]. Other investigators have shown 
that somatostatin analogues could induce regression of both hypergastrinemia-related [19] and sporadic [20] gastric NETs. It appears that somatostatin analogues are well suited for the management of metastatic gastric carcinoid, as they exert inhibitory action on both the trophic stimulus (gastrin) and the tumor itself. Various chemotherapeutic agents alone or in combination have been employed for treating metastatic G-NETs. Treatment with cisplatin plus irinotecan was effective against G-NET, with a high response rate and prolonged lifetime [21]. The combination of cisplatin with etoposide maybe the best choice for poorly differentiated G-NET [22]. Selecting the most effective agents using chemosensitivity assay to determines how effective specific chemotherapy agents are against an individual patient's cancer cells is a promising technique currently under investigation [23].

Another interesting finding is marital status is an independent prognostic factor for G-NET. Unmarried patients were at high risk of cancer related death for G-NET. The impact of marital status on cancer survival outcome considered marriage as a means of social support [24]. Unmarried patients are often diagnosed with more advanced tumor stage, and they are also more likely to receive insufficient treatment [25]. They may also less adherence to medical interventions than married patients. The effect of marital status is being increasingly recognized as a determinant of stage at diagnosis, as well as a determinant of the prognosis of treated cancer [25-31]. To our knowledge, our study was the first to report the impact of marital status on G-NETs.

Another significant predictor of outcome was gender. The incidence of NETs is higher in female patients than in male patients [32]. The protective effect of female observed in this study is very interesting. This may be related to the abnormal expression of hormones in men and women.

There are several limitations of our present study. First, there is lack of centralized pathology review and the criteria for the diagnosis of neuroendocrine tumors also changed in the long study periods. Second, the clinical information, such as the burden of the tumors, the quality of surgery, medical therapy is missing in SEER database.

\section{Conclusion}

This large population-based study using SEER data provides an up-to-date estimate of the incidence and prognosis of G-NETs and discloses factors that may be independent prognostic factors. The survival of patients with G-NETs have increased over the past decades, but the exact cause of the observed survival increase remains to be explained.

\section{Acknowledgements}

The authors acknowledge the efforts of the Surveillance, Epidemiology, and End Results (SEER) Program tumor registries in the creation of the SEER database. The interpretation and reporting of these data are the sole responsibility of the authors.

This study was partially supported by grants from the Shanghai Municipal Health Bureau Project (No: 20134406). The funders had no role in the study design, data collection and analysis, decision to publish, or preparation of the manuscript.

\section{Disclosure Statement}

The authors declared no conflicts of interest. 


\section{Cellular Physiology Cell Physiol Biochem 2018;45:389-396 \begin{tabular}{ll|l} 
DOI: 10.1159/000486915 26 2018 & $\begin{array}{l}\text { O 2018 The Author(s). Published by S. Karger AG, Basel } \\
\text { www.karger.com/cpb }\end{array}$
\end{tabular}}

Yang et al.: Gastric Neuroendocrine Tumors Epidemiology

\section{References}

1 Modlin IM, Lye KD, Kidd M: A 5-decade analysis of 13, 715 carcinoid tumors. Cancer 2003;97:934-959.

2 Maggard MA, O'Connell JB, Ko CY: Updated population-based review of carcinoid tumors. Ann Surg 2004;240:117-122.

-3 Crocetti E, Paci E: Malignant carcinoids in the USA, SEER 1992-1999. An epidemiological study with 6830 cases. Eur J Cancer Prev 2003;12:191-194.

4 Yao JC, Hassan M, Phan A, Dagohoy C, Leary C, Mares JE, Abdalla EK, Fleming JB, Vauthey JN, Rashid A, Evans DB: One hundred years after "carcinoid": epidemiology of and prognostic factors for neuroendocrine tumors in 35, 825 cases in the United States. J Clin Oncol 2008;26:3063-3072.

5 Alsina M, Marcos-Gragera R, Capdevila J, Buxo M, Ortiz RM, Barretina P, Vilardell L, Brunet J, Beltran M, Izquierdo A: Neuroendocrine tumors: a population-based study of incidence and survival in Girona Province, 1994-2004. Cancer Epidemiol 2011;35:e49-54.

6 Faivre S, Niccoli P, Castellano D, Valle JW, Hammel P, Raoul JL, Vinik A, Van Cutsem E, Bang YJ, Lee SH, Borbath I, Lombard-Bohas C, Metrakos P, Smith D, Chen JS, Ruszniewski P, Seitz JF, Patyna S, Lu DR, Ishak KJ, Raymond E: Sunitinib in Pancreatic Neuroendocrine Tumors: Updated Progression-Free Survival and Final Overall Survival From a Phase III Randomized Study. Ann Oncol 2017;28:339-343.

7 Yao JC, Shah MH, Ito T, Bohas CL, Wolin EM, Van Cutsem E, Hobday TJ, Okusaka T, Capdevila J, de Vries EG, Tomassetti P, Pavel ME, Hoosen S, Haas T, Lincy J, Lebwohl D, Oberg K, Rad001 in Advanced Neuroendocrine Tumors TTSG: Everolimus for advanced pancreatic neuroendocrine tumors. N Engl J Med 2011;364:514-523.

8 Klimstra DS, Modlin IR, Coppola D, Lloyd RV, Suster S: The pathologic classification of neuroendocrine tumors: a review of nomenclature, grading, and staging systems. Pancreas 2010;39:707-712.

-9 Matsubayashi H, Takagaki S, Otsubo T, Iiri T, Kobayashi Y, Yokota T, Shichijo K, Tada T, Satoh K, Iwafuchi M: Advanced gastric glandular-endocrine cell carcinoma with 1-year survival after gastrectomy. Gastric Cancer 2000;3:226-233.

10 Nikou GC, Angelopoulos TP: Current concepts on gastric carcinoid tumors. Gastroenterol Res Pract 2012;2012:287825.

-11 Kim HJ, Fay MP, Yu B, Barrett MJ, Feuer EJ: Comparability of segmented line regression models. Biometrics 2004;60:1005-1014.

12 Thomas A, Link BK, Altekruse S, Romitti PA, Schroeder MC: Primary Breast Lymphoma in the United States: 1975-2013 J Natl Cancer Inst 2017;109.

13 Nandy N, Hanson JA, Strickland RG, McCarthy DM: Solitary Gastric Carcinoid Tumor Associated with LongTerm Use of Omeprazole: A Case Report and Review of the Literature. Dig Dis Sci 2016;61:708-712.

14 Shen C, Chen H, Chen H, Yin Y, Han L, Chen J, Tang S, Yin X, Zhou Z, Zhang B, Chen Z: Surgical treatment and prognosis of gastric neuroendocrine neoplasms: a single-center experience. BMC Gastroenterol 2016;16:111.

15 Higham AD, Dimaline R, Varro A, Attwood S, Armstrong G, Dockray GJ, Thompson DG: Octreotide suppression test predicts beneficial outcome from antrectomy in a patient with gastric carcinoid tumor. Gastroenterology 1998;114:817-822.

-16 Richards ML, Gauger P, Thompson NW, Giordano TJ: Regression of type II gastric carcinoids in multiple endocrine neoplasia type 1 patients with Zollinger-Ellison syndrome after surgical excision of all gastrinomas. World J Surg 2004;28:652-658.

17 Kouraklis G, Misiakos E, Glinavou A, Raftopoulos J, Karatzas G: Management of enterochromaffin-like gastric carcinoid tumour metastasized to the liver. Scand J Gastroenterol 2002;37:246-248.

18 Ferraro G, Annibale B, Marignani M, Azzoni C, D’Adda T, D’Ambra G, Bordi C, delle Fave G: Effectiveness of octreotide in controlling fasting hypergastrinemia and related enterochromaffin-like cell growth. J Clin Endocrinol Metab 1996;81:677-683.

19 Tomassetti P, Migliori M, Caletti GC, Fusaroli P, Corinaldesi R, Gullo L: Treatment of type II gastric carcinoid tumors with somatostatin analogues. N Engl J Med 2000;343:551-554.

20 Caplin ME, Hodgson HJ, Dhillon AP, Begent R, Buscombe J, Dick R, Rolles K, Burroughs AK: Multimodality treatment for gastric carcinoid tumor with liver metastases. Am J Gastroenterol 1998;93:1945-1948. 


\section{Cellular Physiology Cell Physiol Biochem 2018;45:389-396 \begin{tabular}{ll|l} 
DOI: 10.1159/000486915 26, 2018 & $\begin{array}{l}\text { O 2018 The Author(s). Published by S. Karger AG, Basel } \\
\text { www.karger.com/cpb }\end{array}$ \\
\hline
\end{tabular}}

Yang et al.: Gastric Neuroendocrine Tumors Epidemiology

-21 Okita NT, Kato K, Takahari D, Hirashima Y, Nakajima TE, Matsubara J, Hamaguchi T, Yamada Y, Shimada Y, Taniguchi H, Shirao K: Neuroendocrine tumors of the stomach: chemotherapy with cisplatin plus irinotecan is effective for gastric poorly-differentiated neuroendocrine carcinoma. Gastric Cancer 2011;14:161-165.

22 Moertel CG, Kvols LK, O’Connell MJ, Rubin J: Treatment of neuroendocrine carcinomas with combined etoposide and cisplatin. Evidence of major therapeutic activity in the anaplastic variants of these neoplasms. Cancer 1991;68:227-232.

-23 Warner RR: Carcinoid case presentation and discussion: the American perspective. Endocr Relat Cancer 2003;10:489-496.

24 Li Q Gan L, Liang L, Li X, Cai S: The influence of marital status on stage at diagnosis and survival of patients with colorectal cancer. Oncotarget 2015;6:7339-7347.

25 Aizer AA, Chen MH, McCarthy EP, Mendu ML, Koo S, Wilhite TJ, Graham PL, Choueiri TK, Hoffman KE, Martin NE, Hu JC, Nguyen PL: Marital status and survival in patients with cancer. J Clin Oncol 2013;31:3869-3876.

-26 Denberg TD, Beaty BL, Kim FJ, Steiner JF: Marriage and ethnicity predict treatment in localized prostate carcinoma. Cancer 2005;103:1819-1825.

-27 Torssander J, Erikson R: Marital partner and mortality: the effects of the social positions of both spouses. J Epidemiol Community Health 2009;63:992-998.

28 Nelles JL, Joseph SA, Konety BR: The impact of marriage on bladder cancer mortality. Urol Oncol 2009;27:263-267.

29 Johansen C, Schou G, Soll-Johanning H, Mellemgaard A, Lynge E: Influence of marital status on survival from colon and rectal cancer in Denmark. Br J Cancer 1996;74:985-988.

-30 Wang L, Wilson SE, Stewart DB, Hollenbeak CS: Marital status and colon cancer outcomes in US Surveillance, Epidemiology and End Results registries: does marriage affect cancer survival by gender and stage? Cancer Epidemiol 2011;35:417-422.

31 Li Q Gan L, Liang L, Li X, Cai S: The influence of marital status on stage at diagnosis and survival of patients with colorectal cancer. Oncotarget 2015;6:7339-47.

32 Navalkele P, O’Dorisio MS, O’Dorisio TM, Zamba GK, Lynch CF: Incidence, survival, and prevalence of neuroendocrine tumors versus neuroblastoma in children and young adults: nine standard SEER registries, 1975-2006. Pediatr Blood Cancer 2011;56:50-57. 